\title{
Recent Trends in Veterinary Diagnostics- A Boon to Reticent diseased Animals
}

\author{
Amritpal Singh $\mathrm{K}^{*}$ and Gagan Preet Kour B \\ Department of Zoology and Environmental Sciences, India \\ *Corresponding author: Amritpal Singh Kaleka, Department of Zoology and Environmental Sciences, Patiala-147002, Punjab, India \\ Submission: 酱 December 26, 2017; Published: 望 January 18, 2018
}

\begin{abstract}
The aim of medicine is to prevent disease and prolong life; the ideal of medicine is to eliminate the need of a physician.

Keywords: Tuberculosis; Cytokine; Trypanosoma; Polymorphism

Abbreviations: ELISA: Enzyme-Linked Immunosorbent Assay; LAMP: Loop Mediated Isothermal Amplification; RAPD: Randomly Amplified

Polymorphic DNA; AFLP: Amplified Fragment Length Polymorphism
\end{abstract}

\section{Introduction}

Diagnosis forms an integral component of disease management and prevention, a small outbreak of disease can spread and pose threat to the entire population. The animal disease diagnostics forms the connecting link between the cause and cure of disease. The cause of death provides vital information when deciding a treatment plan for other animals. The setting up of specialized laboratories across the nation is of major concern to animal health. Without disease diagnostics, food and animal safety would not be reliable.

The initial move in the disease diagnostics is of the producer/ owner of the farm/breeding centre who submits the affected animal to the laboratory at an earliest. A major thrust in the development in animal disease diagnostics has been towards the rapid methods that can provide a definitive answer in less than $24 \mathrm{hrs}$ or even during the course of initial examination of the animal. To achieve such rapidity, the methods should fulfill the prerequisites of speed, simplicity, sensitivity, specificity, reproducibility and low cost. The tests for the specific diagnostics are generally of two types: tests that demonstrate the presence of the infectious agent, major antigens expressed by the agent or its nucleic acid and tests that demonstrate the presence of the antibodies against the infectious agent [1]. The conventional diagnostic methods are time consuming, lesser sensitive and not applicable in the diagnosis of morphologically similar organisms. The recent molecular techniques like DNA hybridization assays, polymerase chain reaction and its modifications have changed the prospective of disease diagnosis.

New powerful diagnostic tools have been developed with the advancement in molecular biology. Refined diagnostic techniques like bio-sensors and Nano-based techniques are increasingly receiving greater attention. The present communication deals with the recent and advanced veterinary disease diagnostics.

\section{Immunoassays}

Traditional immunoassays for the diagnosis of animal diseases were based on detection of antibody to the pathogen, using techniques such as virus neutralisation, enzyme-linked immunosorbent assay (ELISA), complement fixation and agar gel immune diffusion. These generally rely on the interaction of serum polyclonal antibodies against the agent of interest, followed by the use of a detection system [2]. The recent methods such as cloning of genes, over expression vectors and peptide synthesis have made possible the production of specific proteins or proteins that serve as target antigens or positive control reagents in existing and newly-developed immunoassays. The specific positive control is being included in these assays by the use of synthetic peptides (those produced by connecting amino acids together in a specified sequence).

Recently, commercial assays to detect cell mediated responses have become available which includes gamma interferon assays for use in primates and cattle for the detection of tuberculosis [2]. These assays use gamma interferon (Cytokine) expression as an important parameter for disease diagnosis. The host-species specific monoclonal antibodies form the diagnosis basis for these assays.

\section{Nucleic Acid Diagnostics}

The nucleic-acid based techniques (PCR), real time PCR, loop mediated isothermal amplification (LAMP) [3], etc have the 
advantage of ensuring the detection of infection in the latent phase of the disease when the level of infection is often below the detection limit of conventional methods as well as in the assessment of the success of the specific chemotherapeutic intervention, besides its epidemiological applications [4]. Nucleic acid amplification-based detection methods are highly specific, sensitive, instant and reliable. The variants of PCR such as randomly amplified polymorphic DNA (RAPD), amplified fragment length polymorphism (AFLP), amplification refractory mutation system-PCR [5] and RFLP are also useful for species-specific diagnosis, genotyping (DNA polymorphism) and hence in epidemiological studies of parasites. RAPD enables to differentiate the species of Trypanosoma, Theileria and Babesia [6-8].

\section{Biosensors}

A new approach in animal disease diagnosis is the biosensors. Biosensor is a term extensively applied by bioanalytical chemists describing an approach or device which converts a biological event (e.g. immune responses) into a physical, measurable signal [9]. Biosensors when coupled to sophisticated instrumentation produce highly specific analytical tools. Some of the transducer technologies under development include electrochemistry, reflectrometry, resonance and fluorimetry. In addition, nanotechnologies, although in its budding stages, hold the promise of screening for numerous pathogens in a single assay.

The diagnostics can be improved with the inclusion and updation of validated assay systems to ensure better and improved facilities as per latest trends in the field of veterinary sciences. In general, these recent advances in the veterinary diagnostics will be fruitful to safeguard the animal health.

\section{References}

1. Deb R and Chakraborty S (2012) Trends in veterinary Diagnostics. Journal of Veterinary Science and Technology 3: e103.

2. Schmitt B and Henderson L (2005) Diagnostic tools for animal diseases. Revue Scientifique et technique (International office of Epizootics) 24(1): 243-256.

3. Parida M, Sannarangaiah S, Dash PK, Rao PV, Morita K, et al. (2008) Loop mediated isothermal amplification (LAMP): A new generation of innovative gene amplification technique; Perspectives in clinical diagnosis of infectious diseases. Rev Med Virol 18(6): 407-421.

4. Gasser RB (2006) Molecular tools-Advances, opportunities and prospects. Vet Parasitol 136(2): 69-89.

5. Munoz C, Talquenca S G, Volpe M L (2009) Tetra primer ARMS-PCR for identification of SNP in beta-tubulin of Botrytis cinerea responsible of resistance to benzimidazole. Journal of Microbiological Methods 78(2): 245-246.

6. Duarte DP, Tavares KCS, Lazzarotto CR, Komati LKO, Bahia D, et al. (2014) Genetic profile of two isolates of Trypanosoma evansi from southern Brazil with different parasotemias. Biotemas 27(3): 73-80.

7. Zaeemi M, Haddadzadeh H, Khazraiinia P, Kazemi B, Bandehpour M (2011) Identification of different Theileria species (Theileria lestoquardi, Theileria ovis and Theileria annulata) in naturally infected sheep using nested PCR-RFLP. Parasitology Research 108(4): 837-843.

8. Noaman V, Shayan P (2010) Comparison of microscopy and PCR-RFLP for detection of Anaplasma marginale in carrier cattle. Iranian J Microbiol 2(2): 89-94.

9. Zhou Q Kwa T, Liu Y, Revzin A (2012) Cytokine biosensors: the future of infectious disease diagnosis? Expert Review of Anti-Infective Therapy 10(10): 1079-1081. 